\title{
Interacciones entre lo nacional y lo corpóreo. El caso de Arantxa en la serie Patria
}

\author{
Ana Quiroga Álvarez | anaquiro@ucm.es anq1990@gmail.com \\ Investigadora independiente
}

Palabras clave
"historia de España"; "sociología"; "lenguaje
cinematográfico"; "relaciones interpersonales";
"incapacidad"
Sumario
1. Introducción
1.1. El cuerpo como sujeto social: el caso de
Patria
1.2. El contexto: el conflicto vasco mediatizado
1.3. Objetivos
1.4. Hipótesis
2. El marco cualitativo
3. Análisis del cuerpo a través de la sujeción
3.1. La resistencia interna: el cuerpo como
frontera
3.2. Resistencias externas: Miren y Celeste
4. Discusión: afrontar la "no violencia" desde el
gesto limitado
5. Conclusiones
6. Bibliografía.

\section{Resumen}

Este artículo pretende analizar cómo Arantxa hace frente a su condición como persona dependiente en la serie Patria. El objetivo principal es demostrar cómo Arantxa se comunica con sus cuidadoras a través de los gestos limitados que le permite su parálisis. A su vez, se busca demostrar cómo Arantxa se niega a seguir la línea ideológica de su madre, revelándose contra ella a través del proceso de sujeción. Para ello, se apuesta por un método cualitativo en el que el cuerpo de Arantxa se posiciona como centro del análisis. Frente a su lucha por alcanzar la sujeción, se le presentan dos tipos de resistencia: una resistencia interna, determinada por las limitaciones físicas de su cuerpo; y una resistencia externa, cristalizada en las figuras de Miren y Celeste, que determinarían en última instancia la interrelación de Arantxa con su entorno.

Pese al control que ejercen sus cuidadoras sobre ella, Arantxa logra imponer su voluntad y apostar por una resolución no violenta del conflicto. Tomando el cuerpo como eje central, este texto profundiza en otras cuestiones como la identidad nacional o el cuestionamiento de la violencia.

\section{Cómo citar este texto:}

Ana Quiroga Álvarez (2021): Interacciones entre lo nacional y lo corpóreo. El caso de Arantxa en la serie Patria, en Miguel Hernández Communication Journal, Vol 12 (2) pp. 311 a 331. Universidad Miguel Hernández, UMH (Elche-Alicante). DOI: 10.21134/mhjournal. v12i.1327 


\title{
Interactions between the national and the corporeal. The case of Arantxa in the series Patria
}

\author{
Ana Quiroga Álvarez | anaquiro@ucm.es anq1990@gmail.com \\ Investigadora independiente
}

\author{
Keywords \\ "Spanish history"; "sociology"; "film language"; \\ "interpersonal relations"; "disabilities". \\ Summary \\ 1. Introduction \\ 1.1. The body as a social subject: the case of Patria \\ 1.2. The context: the Basque conflict through the \\ media \\ 1.3. Objectives \\ 1.4. Hypothesis \\ 2. The qualitative approach \\ 3. Analysis of the body through subjection \\ 3.1. The internal resistance: the body as a barrier. \\ 3.2. External resistance: Miren and Celeste \\ 4. Discussion: facing "non-violence" through the \\ limited gesture \\ 5. Conclusion \\ 6. Bibliography
}

\begin{abstract}
This paper aims to analyze how Arantxa faces her condition as a disabled person in the series Patria. The main objective is to illustrate how Arantxa communicates with her caregivers through limited gestures allowed by her paralysis. At the same time, this essay seeks to demonstrate how Arantxa rejects her mother's ideology, as she turns against her through the process of subjection. To this effect, the body of Arantxa will be at the center of the analysis, developed through a qualitative approach. As Arantxa tries to achieve the subjection, she faces two kinds of resistance: an internal resistance, determined by her body's physical limitations; and an external resistance,
\end{abstract} crystallized into the figures of Miren and Celeste, who ultimately influence the way in which Arantxa interacts with her social setting. Despite the control exerted on Arantxa by her caregivers, Arantxa imposes her wish to resolve the conflict in a non-violent way. Using the body as the centre of the analysis, this paper delves into other questions such as national identity or the questioning of violence.

Ana Quiroga Álvarez (2021): Interacciones entre lo nacional y lo corpóreo. El caso de Arantxa en la serie Patria, en Miguel Hernández Communication Journal, Vol 12 (2) pp. 311 a 331. Universidad Miguel Hernández, UMH (Elche-Alicante). DOI: 10.21134/mhjournal. v12i.1327 


\section{Introducción}

\subsection{El cuerpo como sujeto social: el caso de Patria}

En el mes de septiembre del 2020, se estrenaba en España la serie Patria, una producción audiovisual creada por Aitor Gabilondo y realizada bajo la dirección de Félix Viscarret y Óscar Pedraza. La serie, producida por Alea Media, ha sido principalmente distribuida por streaming a través de la plataforma digital HBO. Se trata de un producto audiovisual creado a partir de la novela homónima de Fernando Aramburu. Un relato de ficción que recoge la crispación de la sociedad vasca desde los años noventa hasta 2011, año en el que se anuncia el cese definitivo de la actividad armada de ETA.

La novela parte de las vivencias de dos familias, estructuradas en torno a dos mujeres: Miren y Bittori. La primera está casada con Joxian, es madre de tres hijos y su situación económica es ciertamente precaria. La segunda está casada con Txato, empresario, y es madre de dos hijos. Esta diferencia en lo económico conduce a una distinción en lo social, que lleva a Miren a mirar celosamente a Bittori desde el inicio.

Pese a esta pequeña rivalidad, ambas logran construir una relación de proximidad, determinada principalmente por el apego que muestra Arantxa con Nerea, hija de Bittori, desde que son niñas hasta que, ya mayores de edad, Arantxa se casa y Nerea se marcha a Zaragoza a estudiar derecho. Una afinidad que se da igualmente entre Joxian y Txato, que comparten su afición por el ciclismo.

Ambos vínculos se ven afectados desde el momento en que Txato pasa a formar parte de uno de los objetivos de ETA, organización en la que milita Joxe Mari, hermano de Arantxa. Temeroso y marcado por el fuerte carácter de Miren, Joxian acaba distanciándose de Txato cuando comienzan a ver las primeras pintadas amenazantes. Finalmente, el Txato es asesinado por Joxe Mari, hecho que alejará definitivamente a Miren de Bittori, al confirmarse esta noticia por los principales medios del país.

Varios años después del asesinato de Txato $^{1}$, Bittori vuelve al pueblo, intentando recuperar su espacio. En ese nuevo contexto, donde las posibilidades de un rencuentro entre Bittori y Miren parecen haberse borrado por completo, la figura de Arantxa, en silla de ruedas y bajo la vigilancia de su madre, se convierte en un elemento clave que permitirá a Bittori conocer la verdad acerca del asesinato de su marido.

Tras haber sufrido un ictus, Arantxa se ve condicionada a la figura materna, que ha de proveerla de todos los cuidados necesarios. Impedida de toda autonomía y tras haber perdido la custodia de sus hijos, el control que ejerce Miren sobre ella no hace más que acrecentar la rivalidad que existía entre ellas. Habiendo abandonado el hogar a una edad muy temprana para casarse y tener hijos, la minusvalía que le lleva a resistir en una silla de ruedas no hace más que incentivar ese rencor inicial, marcado igualmente por el rechazo absoluto de Arantxa a la violencia y el apoyo de su madre a su hijo Joxe Mari y a los actos que comete.

${ }^{1}$ Tanto en la novela de Aramburu como en la serie de Viscarret y Pedraza se presentan tres espacios referenciales: los años previos al asesinato del Txato, el momento concreto del asesinato y la vuelta de Bittori al pueblo, que tiene lugar tras el alto al fuego definitivo de ETA. 
En esta línea, Arantxa parece posicionarse más próxima a esa figura paterna, arrepentido de haber abandonado a su amigo tras la muerte de este, que de su madre, cuyo rechazo emocional precede a su situación de dependencia. Así, la huida del hogar de Arantxa ha de leerse de la mano de su apoyo constante a Gorka, su hermano escritor que, como ella, se ve forzado a abandonar el hogar y el pueblo ante la coacción social. Si bien a lo largo de la novela y de la serie se observa cómo Arantxa tendría un posicionamiento progresista en cuanto a ideología se refiere, el vértice de su lucha lo genera el rechazo absoluto a la violencia que representa su hermano.

Siendo consciente de la responsabilidad de su hermano Joxe Mari en el asesinato del Txato, Arantxa busca el diálogo con Bittori desde el momento en el que esta vuelve al pueblo. Un acercamiento que se traduce en pequeñas muecas cómplices con Celeste, la mujer a la que Miren contrata para hacerse cargo de parte de los cuidados de su hija, y que le permiten comunicarse con Bittori cuando su madre no está presente. Gracias a ello, Bittori podrá obtener finalmente la confesión de Joxe Mari acerca de su implicación en la muerte de Txato.

En esta línea, el objeto de estudio de esta investigación no es otro que los ejes relaciones que se construyen entre Arantxa y sus dos cuidadoras ${ }^{2}$. Una interacción que se construye a partir de muecas o miradas significativas. Un modo limitado pero preciso a través del cual Arantxa logra hacer frente a las restricciones que se le ponen desde ese exterior hostil, alcanzando la sujeción y asumiendo un rol activo.

\subsection{El contexto: el conflicto vasco mediatizado}

Para comprender el verdadero alcance de Patria, conviene asomarse a la genealogía audiovisual del conflicto. Tal y como recoge Santiago de Pablo, es a partir de la Guerra Civil española cuando comienza a hacerse visible una doble perspectiva de la realidad vasca: "el oasis bucólico y rural y la Euskadi resistente frente a la agresión exterior" (De Pablo y Barrenetxea Marañón, 2006: 172).

Junto a la republicana y a la nacionalista vasca, De Pablo y Barrenetxea señalan una tercera vía, la franquista, que canalizaría su discurso en contra de las facciones más conservadoras del movimiento independentista vasco, apoyado por las bases del PNV y de la Iglesia vasca ${ }^{3}$ (De Pablo y Logroño, 1993).

${ }^{2}$ Si bien se comprende el peso simbólico que tiene la figura de Bittori en la evolución personal de Arantxa, se ha optado por la figura de Celeste, al ser ella quién se encarga directamente de los cuidados de Arantxa, contraponiéndose igualmente a la figura dominante de Miren.

${ }^{3}$ Esta presencia eclesiástica se vislumbra en Patria a través de la figura del cura, que acoge a Miren, intenta que Bittori no vuelva al pueblo y anima a Gorka a apoyar a su hermano con su trabajo literario. En este punto, el modo en el que la familia y amigos de Gorka intentan convencerlo para que apoye la lucha armada a través de sus textos desvela una de las claves de ETA: el apoyo popular es decisivo en el sostenimiento político y económico de la organización (Ballesteros, 2018). 
En cuanto a la producción audiovisual, cabe destacar filmes como Ama Lur (Basterretxea y Larruquert, 1968), que recoge el sentimiento bucólico independentista. En este punto, De Pablo (1999) destaca el documental coproducido entre el País Vasco y Francia, Euskadi hors d'État (MacCaig, 1983); y Gernika, el espiritu del árbol, documental coproducido entre el Reino Unido y el País Vasco (Boulting, 1987).

En los últimos años, el enfoque audiovisual de la cuestión vasca parece alejarse del carácter rígido del documental, abordando el conflicto desde el humor, como es el caso de Ocho apellidos vascos (Martínez, 2014) o asumiendo un matiz social que aborda temáticas como la presencia de las mujeres en el conflicto o la homosexualidad (Sánchez Recio, 2017), ambas presentes en la narrativa de Patria (Viscarret y Pedraza, 2020).

En el caso de la televisión y las plataformas en streaming, es a partir de los 2000 cuando la ficción televisiva comienza a interesarse decididamente por el conflicto vasco (Mota Zurdo, 2020). Dentro de las series, Mota Zurdo distingue dos agrupaciones temáticas: aquellas que abordan directamente la cuestión de ETA y aquellas que la incluyen indirectamente en alguna de sus emisiones. Dos categorías que evolucionarían hasta el presente, con títulos como Presunto Culpable (Cister, Holgado y Montánchez, 2018) o La línea invisible (Barroso, 2020).

Frente a otro tipo de producciones, el carácter híbrido de Patria permite la recreación de los acontecimientos narrados a través de la ficción. Una categoría a la que François Jost se refiere con el término de "docudrama", el cual se caracterizaría por unir aquellos elementos narrativos que asocia al "modo claro" y que "mantienen afirmaciones verdaderas sobre nuestro mundo" con otros característicos de la ficción (Jost, 2001: 19). Así, el cese oficial del fuego de ETA en 2011 es reflejado en la serie a través de totales de las piezas informativas emitidas ese mismo día (10 de enero de 2011). De este modo, las imágenes de los informativos formarían parte de ese "modo claro", mientras que la construcción de los personajes y su evolución se adscribirían a la ficción.

En esta línea, la ficción de Patria apuesta por una voz narrativa en femenino plural que va más allá de las figuras masculinas. Siendo Joxe María el asesino y el Txato la víctima, es en el dolor de Bittori, la viuda, y de Arantxa, el vehículo del perdón, donde se centra la acción. Un planteamiento que rompería con la representación clásica de "el viejo héroe" (Cappello, 2017: 164), superando ese panorama desolador que caracteriza a series extranjeras como Mad Men (Weiner, 2007-2015) o Los Soprano (Chase, 19992007) para apostar por un retrato más próximo. Gracias a este particular enfoque, Patria logra alejarse de lo épico y centrarse en lo cotidiano, fortaleciendo al mismo tiempo una voz en femenino plural que logra ofrecer otra visión del conflicto.

\subsection{Objetivos}

Partiendo del cuerpo de Arantxa como epicentro del análisis, esta investigación persigue los siguientes objetivos:

Ahondar en la evolución que experimenta Arantxa tras el ictus que paraliza 
la mitad de su cuerpo, estudiando cómo su relación con sus cuidadoras determina su interacción final con el entorno.

- Estudiar la influencia que ejercen sobre Arantxa las figuras de Miren y Celeste, analizándolas comparativamente y observando las diferencias que se encuentran entre ellas.

- Demostrar cómo el rechazo de Arantxa hacia toda muestra de violencia se refleja en el modo distante que caracteriza su relación con su madre.

\subsection{Hipótesis}

- Se presentan a continuación las hipótesis de las que parte este artículo. Estas serán refutadas o verificadas tras el estudio del caso:

- El modo en el que Arantxa se comunica con Bittori es un claro ejemplo del poder de denuncia de la "no-violencia", concepto trabajado por Judith Butler en su obra La fuerza de la no-violencia.

- La relación que se establece en Patria entre los personajes femeninos convierte a la serie en un ejemplo necesario para la construcción de narrativas realmente inclusivas donde las mujeres superan el estado pasivo de la acompañante del héroe.

El personaje de Arantxa muestra la realidad de las personas dependientes en la sociedad actual. El hecho de que ella no solo se enfrente a su madre, sino que logre una vía de diálogo con Bittori, demuestra que las personas dependientes son igualmente sujetos activos. La acción, en este sentido, se demuestra por su capacidad para construir redes, y no tanto por sus limitaciones físicas.

\section{El marco cualitativo}

Esta investigación parte de una metodología cualitativa de carácter transversal. Tomando el caso del personaje de Arantxa como eje central del análisis, se cuenta igualmente con un marco teórico diverso que parte de las aportaciones de Judith Butler en torno al concepto de "no-violencia" (Butler, 2020) y de sujeción (Butler, 2015) para profundizar acerca de las personas con "diversidades funcionales" (Guzmán y Platero, 2012: 125) y del alcance que pueden tener las acciones de estas, pese a las limitaciones físicas presentes.

En la línea de precedentes investigaciones como Otro arquetipo femenino es posible: Interseccionalidad en Orange is the New Black (Aguado Peláez y Martínez García, 2015), se pretende abordar la cuestión de la narrativa televisiva desde una mirada global que atienda a los diferentes aspectos que se mencionan en la ficción elegida. Si bien Aguado Peláez y Martínez García se centran en el caso estadounidense, en esta ocasión se ha optado por la ficción española.

Al igual que sucede en el artículo de Eva Hernández (2021), se ha optado por seguir 
un modelo de análisis de corte cualitativo a partir de una figura teórica. Así, este artículo se ha decantado por la figura de Judith Butler por su trayectoria discursiva en torno a los cuerpos y sus posibles mutaciones evolutivas.

Partiendo del concepto de resistencia y sujeción que se recoge en Mecanismos psíquicos del poder. Teorías sobre la sujeción (Butler, 2015), se ha extrapolado dos tipos de resistencias. De esta manera, se distingue entre aquella que atañe directamente al cuerpo de la protagonista (o resistencia interna) y aquella que parte de esta primera y afecta al modo en que ese cuerpo se relaciona con otros (resistencia externa).

\section{Análisis del cuerpo a través de la sujeción}

A la hora de afrontar el análisis del caso de Arantxa, se ha considerado pertinente contar con un marco teórico adecuado que nos permita afrontar la cuestión de la dependencia y de la diversidad funcional. En este sentido, las aportaciones de Lucas Platero y Paco Guzmán han de sumarse a otras investigaciones acerca del debate de la dependencia entre Judith Butler y Eva Kittay (Clifford-Simplican, 2015) o la matización del dolor de los cuerpos dependientes (Price, 2015), entre otros estudios al respecto. Un enfoque que parte del axioma teórico de Butler en torno a la sujeción, concepto que extrae de su interpretación a los postulados de Althusser y Foucault.

Concretamente, el concepto de sujeción, referido por Butler, es un préstamo extraído del trabajo de Michel Foucault en Vigilar y castigar (Foucault, 1975). Tomando al sujeto sometido como epicentro del análisis, lo que buscaría Foucault es profundizar en los mecanismos que permiten al sistema dominante controlar y limitar la acción de dicho sujeto. Unos sistemas de dominación que Foucault denomina como "sistemas de castigo" (Foucault, 1975: 30) y que ejercerían su poder tanto a través de técnicas represivas como de medidas disuasorias, cuyo objetivo no sería otra que sugestionar al individuo a aceptar ese sometimiento y a naturalizar ese control sobre su cuerpo.

Cabe citar igualmente la influencia del trabajo de Althusser en la interpretación que realiza Butler de la resistencia como última vía de escape de ese individuo sometido (Lampert, 2015) En el caso que nos ocupa, la resistencia como concepto es vital para comprender el proceso evolutivo de Arantxa y su capacidad para asumir esa presión sistemática, somatizada en el gesto mínimo, y desplazarse hacia la resignificación (o liberación) a través del diálogo.

Así mismo, esta investigación apuesta por un enfoque interseccional donde los estudios de género converjan directamente con el "Disability Rights Movement" (Bonan, Lopes, Gesser y Filgueiras Toneli, 2019), movimiento que en los últimos veinte años ha ido rechazando progresivamente el enfoque biomédico de las diversidades funcionales ${ }^{4}$, apostando por una revisión global del feminismo donde los cuidados sean una prioridad.

${ }^{4}$ Si bien la Unesco señala la preferencia de usar el término "incapacidad", en la presente investigación se ha optado por seguir el término de "diversidad funcional" (Guzmán y Platero, 2012: 125). 


\subsection{La resistencia interna: el cuerpo como frontera}

Tras el ictus, Arantxa ha de aprender a convivir con su nuevo estado, aceptando las condiciones que le impone la parálisis de la mitad de su cuerpo. Una adaptación en la que hay que tener en cuenta un factor determinante: el rechazo de Arantxa hacia la violencia que representa su hermano y que su madre ampara.

En este punto, Amber Knight sostiene que todos los seres humanos son susceptibles de experimentar diversidad funcional a lo largo de sus vidas. Así, Knight considera que, de cara a hacer frente a las posibles vulnerabilidades que los miembros de una sociedad puedan experimentar, es preciso apostar por la construcción de "responsabilidad colectiva" (Knight, 2013: 17).

En la línea de Knight, el personaje de Arantxa visibiliza la hipótesis defendida por la autora: el ser humano es vulnerable por naturaleza. El hecho de que Arantxa pase de ser una madre independiente a recuperar el rol de hija que precisa de los cuidados de su madre lleva al espectador a ser consciente de la fragilidad humana. Es esta condición la que conduce a Knight a defender la necesidad de reforzar un sistema público de salud lo suficientemente fuerte como para que las personas que experimentan diversidad funcional puedan vivir dignamente, sea cual sea su condición socio-económica (Knight, 2013: 21).

Es interesante remarcar cómo los padres de Arantxa pueden hacer frente a la situación que atraviesa su hija, disponiendo de un mobiliario adaptado para ella y de los cuidados que el sistema público de salud le posibilita. En este sentido, en el caso de Arantxa la resistencia interna se libera de la carga socio-económica. Algo que no sucede en el caso de algunos de los testimonios recogidos en ese artículo de Amber Knight.

Atendiendo a la dimensión emocional, uno de los principales escollos que ha de afrontar Arantxa es el de su propio reflejo. Pese a los intentos de su madre por construir una cotidianidad soportable, el rechazo de Arantxa denota su miedo ante ese nuevo estado corporal. En este punto, el cuerpo adquiere la dimensión de una cárcel que limita cada impulso y al que debe acostumbrarse: "Aprisionada en un cuerpo inerte. Una mente cautiva en una armadura de carne. En eso se había transformado" (Aramburu, 2016: 534).

Retomando el trabajo de Judith Butler en Mecanismos psíquicos del poder. Teorías sobre la sujeción, podríamos considerar la dificultad de Arantxa para habitar su cuerpo tras el ictus como una primera resistencia de carácter interno en la que el sujeto toma consciencia de su opresión. Gracias a ella, Arantxa puede desplazarse hacia una segunda resistencia de carácter externo, donde el cuerpo, sujeto consciente de su situación, entra en contacto con su entorno más cercano y se aproxima hacia la pena sujeción.

El proceso por el cual Arantxa acepta su nuevo estado de dependencia es arduo y lento. Ese camino hacia la plena “sujeción” (Butler, 2015) germina en el momento en el que Arantxa asume su condición de dependencia. Un aspecto que se refleja en el tercer episodio de la serie, que recoge en un plano medio a Arantxa caminando con la 
ayuda de dos enfermeras (fotograma $1^{5}$ ).

Figura 1. Fotograma de la serie Patria (Viscarret y Pedraza, 2020). En streaming en HBO (C)

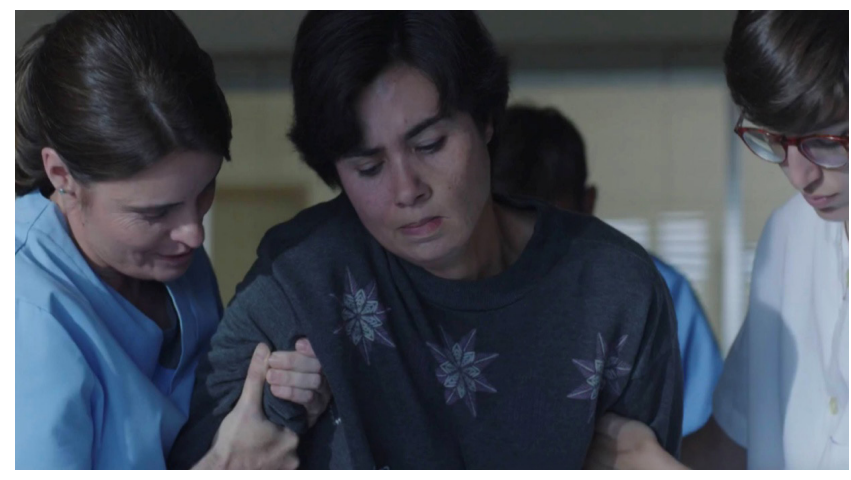

Ocupando el centro del encuadre, la mueca leve pero visible que muestra su rostro es clave para entender ese momento de aceptación. En ese instante, Arantxa entiende que necesita ayuda externa para cada gesto cotidiano. Afrontando el dolor, el rechazo a su propio reflejo se desvanece para dejar paso a un nuevo estado en el que la aceptación le permitirá asumir esa dependencia hacia los demás en cada movimiento.

Dentro de esa toma de conciencia inicial de carácter interno, uno de los factores que determinan la evolución del personaje es su intento de comunicarse con el exterior. Ante la imposibilidad de hacerlo a través del habla, Arantxa recurre a aquellos gestos que le permite su limitada movilidad. Acciones pequeñas, como un leve guiño o un gruñido apenas audible, que adquieren una notable carga simbólica dentro del contexto que las determina.

Siendo consciente de sus limitaciones, Arantxa no deja de reivindicar su lugar como sujeto consciente, cristalizando en ese gesto mínimo su rechazo hacia la violencia de ETA que defiende parte de su familia. Asumiendo su opresión, los pequeños gestos canalizan su energía y reiteran su presencia en un entorno inhóspito. Según Margaret Price, estos gestos, que podrían ser sinónimos de dolor (tanto mental como físico), adquieren dentro del contexto de opresión de las personas dependientes un matiz reivindicativo que toma presencia desde la disidencia (Price, 2015).

Asumiendo la resistencia interna que supone habitar ese cuerpo dependiente, Arantxa puede iniciar entonces ese nuevo reto: la canalización de sus propias emociones a través de la resistencia externa.

${ }^{5}$ Los fotogramas de la serie Patria que se incluyen en esta investigación han sido tomados con un único fin académico, siendo centrales en el análisis que se plantea. Dichas imágenes han sido extraídas de la distribuidora en streaming y plataforma digital HBO. 


\subsection{Resistencias externas: Miren y Celeste}

En la novela de Aramburu, se recoge cómo Miren decide contratar a una asistenta para que le ayude a gestionar los cuidados de su hija. Desde el momento en el que llega Celeste, la novela destaca un cierto desprecio por parte de Miren hacia Celeste y su trabajo. Un despotismo que se vislumbra en las declaraciones de Miren: "Son pobres. Sabrán reconocerlo” (Aramburu, 2016: 66).

Si bien en la serie Celeste es presentada como un personaje más, las miradas de Miren desvelan desde el inicio un cierto descrédito. Un desprecio que se potencia por momentos, especialmente cuando Celeste prioriza las necesidades de Arantxa a las exigencias de Miren, permitiendo de forma indirecta que Arantxa culmine su proceso de sujeción y lo cristalice en las progresivas conversaciones con Bittori ${ }^{6}$.

Figura 2. Fotograma de la serie Patria (Viscarret y Pedraza, 2020). En streaming en HBO (C)

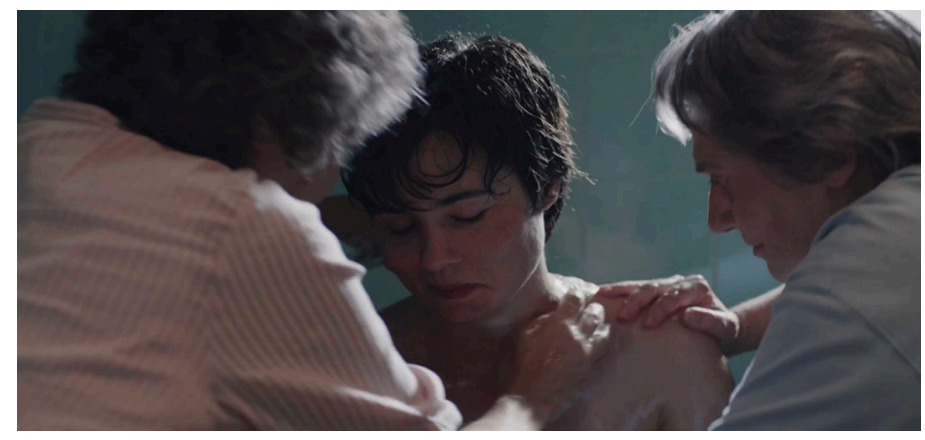

Pese a estos desencuentros, el rol que ejercen Celeste y Miren es retratado desde la horizontalidad, potenciando encuadres fotográficos en los que ambas participan de los cuidados de Arantxa, que permanece ocupando el centro del encuadre. Uno de los ejemplos a destacar se produce en la secuencia del baño del quinto episodio (fotograma 2), que resultará igualmente reveladora para comprender el vínculo que establece Arantxa con cada una de sus cuidadoras.

En ella, se aprecia una composición triangular invertida, ocupando Arantxa el centro del encuadre (fotograma 2). Inmóvil, levemente inclinada hacia delante y con los ojos cerrados, la fuerza simbólica que destila el personaje de Arantxa parece superar en ese instante los límites de su cuerpo, esto es, la resistencia interna. Ante su quietud, destacan las figuras de Celeste (izquierda) y Miren (derecha), que se afanan en asearla.

${ }^{6}$ El desprecio con el que Miren trata a Celeste revela el peso simbólico de la "familia nuclear" (Foucault, 2007), que eleva a Miren al rango de madre y delega a Celeste a la posición de mera cuidadora externa. Una posición que Celeste asume y exterioriza a través de su posición corporal y de su mirada, y que se libera brevemente con Bittori, quién sí es capaz de reconocer el peso de Celeste en la recuperación de Arantxa. 
La horizontalidad que vincula en esa imagen a Celeste y Miren las dispone al mismo nivel. No obstante, la relación que ambas establecen con Arantxa difiere en diversos matices. Tal y como se percibe a lo largo de la narración, el personaje de Miren ejerce un poder vertical sobre Arantxa que se desvanece en el caso de Celeste, que intenta aproximarse a Arantxa.

Miren parece repetir con su hija el mismo modelo conductual que con el resto de miembros de la familia. Adoptando un tono seco y cortante, se aleja del modo afectivo que caracteriza a Celeste y opta por imponer unos ejes conductuales que limitan la carga emotiva con la que se comunica con su hija. Más que guiar y acompañar, Miren establece una relación materno-filial basada en el control y seguimiento.

Aplicando los postulados de Foucault en torno a la sujeción, Miren parece encarnar metonímicamente el control ejercido desde el sistema dominante hacia Arantxa, que representaría a su vez al colectivo con diversidad funcional y a todos aquellos que rechazan la violencia de ETA. Desde su mirada condescendiente hacia Celeste, Miren marcaría los límites de acción hacia su hija. Un modelo conductual que lleva a Miren a controlar cada intento de Arantxa de aproximarse a Bittori ${ }^{7}$, y que explosiona cuando descubre los intentos de su hija por supurar la herida entre las dos familias ${ }^{8}$.

Esta cristalización de los "sistemas de castigo" (Foucault, 1975: 30) se visualiza ya en el primer capítulo, en el que Arantxa acompaña a su madre a misa en contra de su voluntad y acaba escupiendo la hostia que le pone el cura en la boca. Devolviendo la hostia, símbolo de la unión entre fieles, devuelve también el ofrecimiento del cura a seguir los pasos de su madre.

Una acción limitada por la situación de dependencia de Arantxa que, sin embargo, revela con audacia el potencial de la hija para articular su particular resistencia hacia el control materno que simboliza, a su vez, una resistencia indirecta al control que ejerce la sociedad vasca hacia aquellos que denuncian la violencia terrorista.

Esta relación conflictiva entre madre e hija cristaliza en uno de los primeros planos que componen la ya citada secuencia del baño. Confrontada ante el espejo, Arantxa intenta asimilar su nuevo estado. En un primer plano, vemos cómo el rostro de la hija se refleja partido en el espejo (fotograma 3), acompañada del de su madre, también ligeramente fraccionado.

${ }^{7}$ Un momento simbólico tiene lugar en el capítulo segundo, cuando Miren percibe la pulsera que le devuelve Xavier a Arantxa, comprada por Txato cuando eran pequeños.

${ }^{8}$ Cuando Arantxa confiesa que ha sido ella quién ha estado buscando el diálogo entre Joxe Mari y Bittori, Miren se muestra sorprendida. Sin embargo, a lo largo de la serie se observa cómo la postura vigilante de Miren aumenta al mismo tiempo que los intentos de Arantxa por librarse de la figura materna. 
El hecho de que se muestre el reflejo de ambas por encima de sus cuerpos podría interpretarse como la imposibilidad de Miren y Arantxa de encontrarse. En el espejo, ambas aparecen juntas y al mismo nivel. Un destello de horizontalidad que ambas parecen proyectar, pero que está ausente a lo largo de la narración.

Figura 3. Fotograma de la serie Patria (Viscarret y Pedraza, 2020). En streaming en HBO (C)

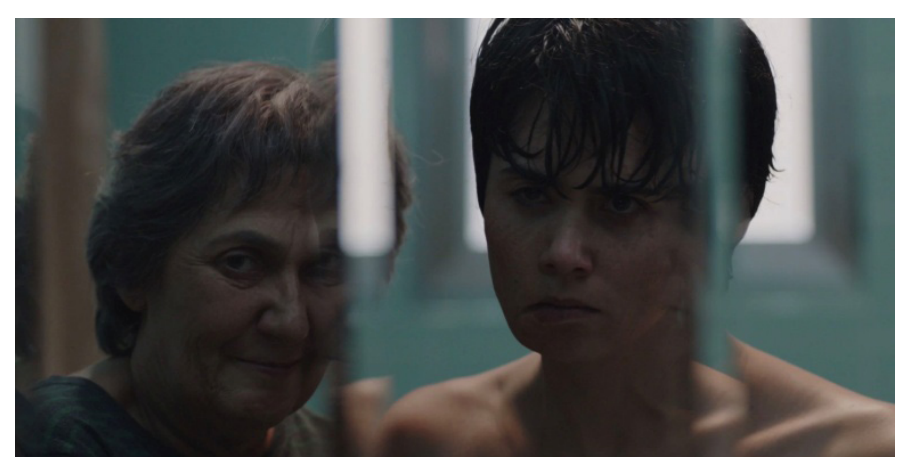

En la doble parcialización del cuerpo de Arantxa se vislumbra su lucha por alcanzar la sujeción, asumiendo la fractura y el dolor de esa resistencia interna que es su cuerpo. Por su parte, la sonrisa enmudecida de Miren revela la tensión que define su relación con su hija. Queriendo acompañarla, no logra comprender las razones que llevan a su hija a contradecirla, instalándose en un sempiterno estado de vigilancia.

Este fotograma sirve a modo de antesala de lo que acontecerá poco más tarde: las progresivas reuniones con Bittori a través de las cuales Arantxa se irá desligando paulatinamente de ese control materno. En el instante que se recoge en la imagen (fotograma 3), la resistencia latente de Arantxa se vislumbra no solo en su gesto seco, sino en esa leve fractura del marco.

Esta fractura relacional se disipa en el caso de Celeste. Así, se pasa de esa imposibilidad real del ser, de la limitación del espejo, a la literalidad carnal de los cuerpos. En esa citada secuencia del baño, la posición de Celeste revela esa búsqueda de un modo diferente de encontrarse con Arantxa. Una muestra de empatía que se desvela en ese plano medio donde Celeste se hace cargo literalmente del peso de Arantxa para ayudar a desvestirla (fotograma 4). Una acción legitimada por la propia Arantxa, que pide que sea Celeste, y no su madre, quien la ayude a ducharse. 
Figura 4. Fotograma de la serie Patria (Viscarret y Pedraza, 2020). En streaming en $\mathrm{HBO}$ C

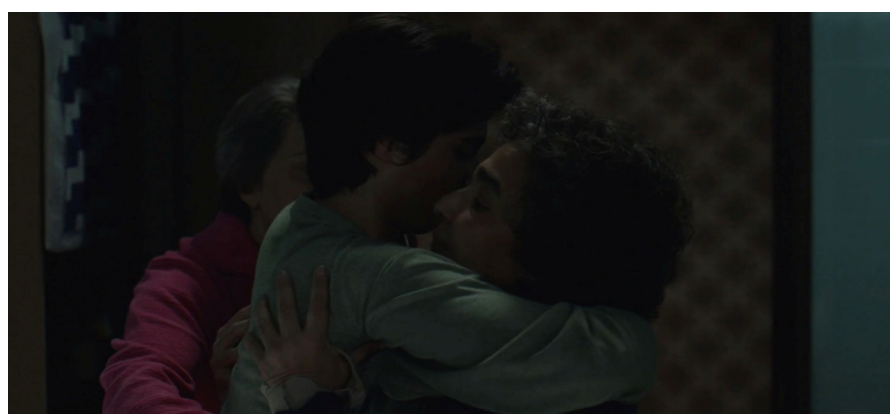

La confianza con la que Arantxa se deja caer en los brazos de Celeste apunta hacia un vínculo afectivo de proximidad. Una interacción gestionada desde la empatía a la que Miren no logra acceder. Tal y como se vislumbra en ese plano medio (fotograma 4), el brazo de Miren sostiene a su hija, pero su rostro es tapado por el de Arantxa, que roza con la mejilla de Celeste en un gesto que parece casi simular el de un abrazo afectuoso.

Una desigualdad relacional se recoge igualmente en el texto de Braswell, en el que el autor muestra a través de su propio relato cómo las relaciones basadas en la dependencia por diversidad funcional condicionan vínculos distorsionados. Parafraseando a Braswell, los “comportamientos de afinidad" (Braswell, 2015: 246) resultan determinantes en la evolución personal de Arantxa, extendiéndose igualmente a la estructura narratológica de Patria.

Pese a las diferencias relacionales que se presentan entre estas tres mujeres, lo relevante de esta secuencia del baño es la ausencia de la figura masculina. Una premisa que se extiende al resto de la narración seriada y que logra aportar un enfoque diferente en torno a la temática del conflicto vasco. Una perspectiva que, de acuerdo con Selisker, permite encajar el trabajo de Viscarret y Pedraza dentro de los parámetros del conocido como Test de Bechdel ${ }^{9}$.

Así, la clave discursiva de Patria reside en esas "redes de mujeres" (Selisker, 2015: 511), que van más allá de las estructuras canónicas de la familia nuclear y revelan la importancia de los cuidados a través del personaje de Celeste, quién posibilita el reencuentro final entre Arantxa y Bittori. Frente a Miren, la figura de Bittori se

${ }^{9} \mathrm{El}$ Test de Bechdel hace referencia al contenido de una viñeta publicada en 1985, dentro de la tira cómica Lesbianas a la que vigilar, de Alison Bechdel. En ella, se plantean los tres elementos centrales para que una obra audiovisual pueda considerarse no misógina: que salgan al menos dos mujeres (punto primero), que estas hablen entre sí (punto segundo) de algo o alguien que no sea un hombre (punto tercero) (Selisker, 2015). 
resuelve como esencial desde la distancia. Al aceptar el perdón de Joxe Mari, Bittori libera a Arantxa de esa culpa, liberando la somatización que venía soportando su cuerpo y abriendo una nueva vía de diálogo.

\section{Discusión: afrontar la "no-violencia" desde el gesto limitado}

A la hora de verificar o refutar laS hipótesis planteadas al inicio, se ha demostrado el modo en el que Arantxa accede al diálogo con Bittori se aleja tanto de la percepción pasiva que la sociedad pueda tener de las personas con diversidad funcional como de la agresividad oral con la que Miren defiende a Joxe Mari. Desafiando la cuestión nacionalista, Arantxa opta por una tercera vía, la de la concordia.

El posicionamiento activo de Arantxa, pero limitado por su parálisis, representa la capacidad de acción desde la "no-violencia" (Butler, 2020). Asumiendo ese dolor como parte del proceso de sujeción, Arantxa afronta la resistencia interna (su propio cuerpo) y las resistencias externas (la presión ejercida desde el entorno social) sirviéndose de estas para lograr su objetivo último: abrir una vía de diálogo entre su hermano Joxe Mari y Bittori ${ }^{10}$.

La clave en el proceso evolutivo de Arantxa reside precisamente en esa renuncia activa a la violencia. Frente a la violencia ejercida por su hermano y aupada por su madre, Arantxa opta por construir sus propias redes de contención que le permitan hacer frente a la presión interna y externa. Una "no-violencia" (Butler, 2020) que no ha de ser confundida con el rechazo a la acción. Desde sus limitaciones motoras, Arantxa logra accionar unos mecanismos que le permiten alcanzar una vía de diálogo.

Para ello, Arantxa parte de una de las premisas que atraviesan The force of non-violence: determinándose de manera introspectiva, el individuo necesita igualmente de los otros para alcanzar la plena sujeción. Esto es, es precisamente a través de las resistencias externas, determinadas por lo social, que Arantxa logra culminar su proceso evolutivo.

Sabiéndose dependiente de los demás, busca en su entorno a aquellos que pueden ayudarle a avanzar. En este sentido, la figura de Celeste resulta determinante por su carácter conciliador, llegando a subvertir en ocasiones los mandatos de Miren (quien la contrata) para atender las necesidades de Arantxa. Una posición mediadora que se revela en esos paseos que Arantxa da con Celeste y que le permiten contactar con Bittori. En esta línea, cabe recordar cómo S.C. Simplican recuerda que la vulnerabilidad del ser humano le lleva a necesitar del otro, a

\footnotetext{
${ }^{10} \mathrm{El}$ dolor como motor hacia la sujeción, recogido en el ensayo de The force of non-violence, aparece igualmente en artículo trabajado de Margaret Price, como esa fuerza que permite a las personas con diversidad funcional asumir su condición y construirse como sujetos activos, consciente de esa opresión que les atraviesa (Price, 2015). Así, Price parece recoger el testigo de Butler en torno a las teorías de la sujeción para apostar por una resiginificación plena de las personas dependientes.
} 
protegerlo. Esa interdependencia justificaría, según Simplican, una política de los cuidados en la que ninguna vida se priorizase sobre el resto ${ }^{11}$.

Esta conciencia inclusiva es la que definiría el acompañamiento continuo de Celeste. Una presencia que Arantxa agradece en gestos mínimos pero contundentes. Gestos limitados que agradecen y suman, y que sirven a Arantxa como vía para cerrar las heridas del pasado. $\mathrm{Al}$ igual que Celeste, Arantxa prioriza la premisa compartida por Butler y Simplican e intenta que nadie se quede atrás.

En relación a esa segunda hipótesis que apelaba al carácter inclusivo de Patria, a lo largo del epígrafe precedente se ha verificado cómo la relación que se establece en la narración entre los personajes femeninos logra subvertir los mandatos de una mirada masculina, ya no sexual, sino narrativa.

Asumiendo su parálisis física y contando con el apoyo de Celeste, Arantxa subvierte a la figura de control (su madre) y apuesta por ese diálogo final con Bittori. A través de esa aproximación con la viuda, Arantxa logra superar la somatización que congela su rostro y logra articular su primera palabra. Una palabra ("madre") que no deja de ser notablemente simbólica, ya que es el rechazo de la violencia que apoya su propia madre lo que le permite hallar la paz con Bittori.

En este punto, la fortaleza que emana de este personaje contradice la visión que la sociedad tiene de las personas con diversidad funcional ${ }^{12}$. Accionando su subjetividad desde una postura no violenta, Arantxa cuestiona no solo la violencia ejercida por su hermano Joxe Mari y respaldada por su madre, sino el silencio de la sociedad que asume esos actos sin condenarlos.

Tal y como sostiene Butler, la lógica de la "no-violencia" se vertebra en la voluntad última del individuo para oponerse a una opresión u opresiones determinadas desde una vía no pacífica, pero sí asertiva (Butler, 2020). Arantxa no centra sus energías en agredir física o verbalmente a los $\operatorname{otros}^{13}$, sino en construir una nueva narrativa que permita no ya el perdón, pero sí la comprensión, la empatía para con el otro.

${ }^{11}$ Precisamente Stacy C. Simplican alude al concepto de "ungrievable lives" (se podría traducir como "vidas que no tienen que ser lamentadas") de Judith Butler para incidir en cómo la sociedad occidental prioriza unas vidas por encima de otras (aquellas racializadas, no occidentales, queers, con diversidad funcional, etc.) (Simplican, 2015: 230).

${ }^{12}$ Tal y como recogen Lucas Platero y Paco Guzmán, desde el momento en el que una persona con diversidad funcional asume un rol activo en cualquiera de sus facetas, ya sea la sexual o la meramente afectiva-relacional, la sociedad responde a ello con descrédito, infravalorando sus acciones (Guzmán y Platero, 2012).

${ }^{13} \mathrm{El}$ hecho de que no busque dañar a los otros no quiere decir que no pueda hacerlo. Como bien demuestra en sucesivas ocasiones con su madre, Arantxa no duda en enfrentarse a ella cuando le agrede. Una respuesta gestionada desde gestos limitados, como miradas o frases que verbaliza a través de su tableta electrónica. 
Con ello, queda verificada la tercera hipótesis planteada al inicio, relativa a cómo el personaje de Arantxa revela las capacidades y potencialidades reales de las personas con diversidad funcional. Un enfoque que contradice la visión de Sartre, quién sostenía que "la no-violencia y la pasividad equivalen a la complicidad" (Ascher y Butler, 2014: 27).

Figura 5.Fotograma de la serie Patria (Viscarret y Pedraza, 2020). En streaming en HBO C

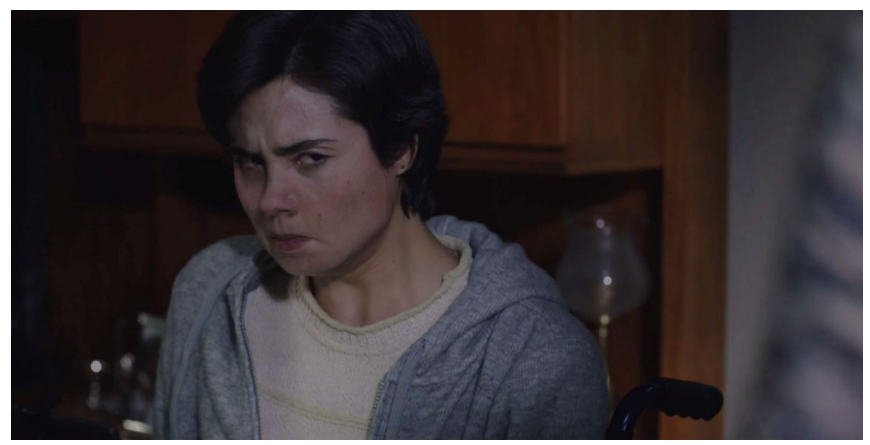

Si bien Sartre sostiene que la "no-violencia" es una forma enmascarada de complicidad, el modo en el que Arantxa construye sus redes de contención frente a las resistencias internas y externas que se le imponen demuestra una fuerza que se desmarca de lo cómplice. Una realidad que se hace visible en cada uno de los gestos, limitados pero eficaces, con los que muestra su desacuerdo.

Muestra de ello es el instante en el que Arantxa responde vehementemente a su madre, tras comunicarle su decisión de despedir a Celeste. Una noticia que Arantxa recibe desde la máxima crispación, siendo esta una de las secuencias donde mejor se percibe esa capacidad para canalizar la ira a través del mínimo gesto de la joven.

Tal y como se observa en ese plano medio (fotograma 5), el gesto de Arantxa se funde con su parálisis. Ante la limitación impuesta por la resistencia interna, entra en una especie de convulsión y comienza a sufrir lo que se podría identificar como un ataque de pánico. Queriendo exteriorizarse y encontrándose con la limitación del cuerpo, la rabia de Arantxa bloquea la respuesta.

En ese gesto abrupto pero limitado, se podría visualizar la somatización del dolor de Arantxa al sentirse incapaz de responder con vehemencia y asertividad al despotismo con el que trata Miren no solo a Celeste, sino a Bittori y a todos aquellos que cuestionan su posicionamiento político. Una limitación somatizada que se resuelve a través del perdón de Bittori y de ese acercamiento final en la plaza. 


\section{Conclusiones}

El modo decisivo con el que Arantxa construye sus propias redes de cuidado y contención, rechazando las posturas polarizadas de su entorno, sirve al público y a la crítica como un ejemplo necesario de la "no-violencia" butleriana. Un posicionamiento narrativo que, cumpliendo con las premisas del Test de Bechdel y asumiendo un relato de la diversidad funcional, sirve de guía para las nuevas ficciones audiovisuales.

Tal y como se ha mostrado a lo largo de este artículo, el personaje de Arantxa se caracteriza por su pleno rechazo a la violencia y a todo tipo de discursos y/o proclamas nacionalistas. Desligándose del sentimentalismo, su objetivo no es otro que lograr que Bittori pueda conocer la verdad acerca del asesinato de su marido. Un gesto que se aleja de lo heroico, siendo Arantxa conocedora de las limitaciones de sus acciones.

Desde su posición oprimida, Arantxa toma conciencia de la herida de Bittori y de sus dimensiones. Una mirada que le lleva a buscar en lo pequeño esa respuesta a lo magnánimo, lo inabarcable: el dolor de las víctimas. Superando el relato melodramático, Patria parece asumir las directrices de Butler, construyendo un relato de la "noviolencia" desde los márgenes. Sin llegar a ser protagonista, Arantxa interpela a la cámara no desde su condición, sino desde su deseo de sujeción.

Una voluntad de acción que estaría en última instancia limitada por la figura materna, encarnando Miren metonímicamente el poder simbólico de ese "sistema de castigo" (Foucault, 1975: 30). Un control que es ejercido tanto directamente, obligando a Arantxa a asistir a misa con ella, como indirectamente, a través de las miradas inquisitivas con las que observa a su hija al sospechar de sus reuniones con Bittori.

Unos mecanismos de control que, en el caso de Miren, deben interpretarse dentro del contexto social vasco, donde la disidencia es castigada con el destierro. Al igual que el cura intenta que Gorka se haga simpatizante del movimiento terrorista a través de sus textos, Miren intenta aprovecharse de ese estado de vulnerabilidad de su hija para forzar un vínculo roto, ya que el rechazo de Arantxa a la lucha armada precede a su condición como dependiente, siendo uno de sus rasgos identitarios.

Como defensora de su hijo Joxe Mari y de los valores bajo los que este actúa, el hecho de que su hija apoye a Bittori lo toma como una traición, no solo a su familia sino a la sociedad. Un dolor que muta asertivamente en ese breve abrazo con Bittori que cierra la serie, a través del cual Miren parece asimilar la posición de su hija y los motivos que le conducen a alejarse de ese ambiente. 


\section{Bibliografía}

Aguado Peláez, D. y Martínez García, P. (2015). Otro arquetipo femenino es posible. Interseccionalidad en Orange is the New Black. Miguel Hernández Communication Journal, 11 (72), pp. 261-280. doi: 10.21134/mhcj.v0i6.93

Ascher, I. y Butler, J. (2014). Violence, non-violence. Actuel Marx, 55 (1), pp. 13-35.

Aramburu, F. (2016). Patria. Barcelona: Tusquets Editores.

Ballesteros, A. (2018). Counter-Terrorism Efforts in Spain. Counter Terrorist Trends and Analyses, 10 (11), pp. 9-13.

Bonan Gomes, R., Lopes, P. H., Gesser, M. y Filgueiras Toneli, M. J. (2019). New Dialogues in Feminist Disability Studies. Estudos feministas, 27 (1), pp. 1-13.

Braswell, H. (2015). My two My Two Moms. Disability, Queer Kinship, and the Maternal Subject. Hypatia, 30 (1), pp. 234-250.

Butler, J. (2020). The force of non-violence. An Ethico-Political Band. Londres: Verso.

- (2015). Mecanismos psíquicos del poder. Teorías sobre la sujección. Madrid: Ediciones Cátedra.

- (2012). Precarious Life, Vulnerability, and the Ethics of Cohabitation. The Journal of Speculative Philosophy, 26 (2), pp. 134-15. doi: 10.5325/jspecphil.26.2.0134

Cappello, G. (2017) El tiempo del cínico. Acerca del héroe de la ficción televisiva. Área Ábierta. Revista de comunicación audiovisual y publicidad 17 (2), 155-166.

De Pablo, S. (1999). Definición nacional e identidad nacionalista a través del cine: dos coproducciones vascas de los años ochenta. Sancho el sabio: Revista de cultura $e$ investigación vasca, 10, pp. 97-108.

- y Logroño, J.M. (1993). Cine y propaganda en el País Vasco durante la guerra civil. Los reportajes franquistas. Filmbistoria online. 3(1-2), pp. 231-238.

- y Barrenetxea Marañón, I. (2006). Del oasis vasco a la Euskadi resistente. El País Vasco en el cine documental extranjero. Historia y politica: Ideas, procesos y movimientos sociales, 15 , pp. 171-190.

Foucault, M. (1975). Surveiller et punir. París: Gallimard.

- (2007). Historia de la sexualidad. 1-La voluntad de saber. México: Siglo XXI Editores. 
Guzmán, P. y Platero, R. L. (2012). Passing, enmascaramiento y estrategias identitarias. Diversidades funcionales y sexualidades no normativas. En R. L. Platero (Ed.), Intersecciones: cuerpos y sexualidades en la encrucijada (pp. 125-158). Barcelona: Edicions Bellaterra.

Hernández Martínez, E. (2021). Atragantamiento en el cine de Pedro Almodóvar. Análisis de Dolor y Gloria. Miguel Hernández Communication Journal, Vol. 12 (1), pp. 243-266. doi: 10.21134/mhcj.v12i.347

Jost, F. (2001). La télévision du quotidien. Entre réalité et fiction. París: Éditions Denoël.

Knight, A. (2013). Disability as Vulnerability. Redistributing Precariousness in Democratic Ways. The journal of politics, 76 (1), pp. 15-26.

Lampert, M. (2015). Resisting ideology. On Butler's critique of Althusser. Diacritics, 43 (2), pp. 124-147.

Mota Zurdo, D. (2020). ETA, Presunto Culpable. El tratamiento del terrorismo vasco y sus víctimas en una serie de ficción. Historia Actual Online, 52(2), pp. 157-169.

Price, M. (2015). The Bodymind Problem and the Possibilities of Pain. Hypatia, $30 \quad$ (1), pp. 268-284.

Sánchez Recio, G. (2017). DE PABLO, Santiago, Creadores de sombras. ETA y el nacionalismo vasco a través del cine, Madrid, Tecnos, 2017, 494 pp. Pasado y memoria: Revista de historia contemporánea. 16, pp. 281-285.

Selisker, S. (2015). The Bechdel Test and the Social Form of Character Networks. New Literary History, 46 (3), pp. 505-523.

Simplican, S. C. (2015). Care, Disability, and Violence. Theorizing Complex Dependency in Eva Kittay and Judith Butler. Hypatia, 30 (1), pp. 217-233.

\section{Filmografía}

Barroso, M. (Director). (2020). La linea invisible. [Serie de televisión]. Movistar+. Recuperado de https://ver.movistarplus.es/

Basterretxea, N. y Larruquert, F. (Directores). (1968). Ama Lur [Película]. Frontera Films Irún S.A.

Boulting, L. (Director). (1987). Gernikea, el espiritu del árbol [Película]. Eresonika. 
Chase, D. (Productor). (1999-2007). The Sopranos [Los Soprano] [Serie de televisión]. HBO. Recuperado de https://es.hboespana.com/

Cister, J., Holgado, J. y Montánchez, A. (Directores). (2018). Presunto culpable [Película]. Atresmedia televisión.

MacCaig, A. (Director). (1983). Euskadi hors d'État [Euskadi fuera de Estado] [Película]. Dathanna.

Martínez, E. (Director). (2014). Ocho apellidos vascos [Película]. Lazonafilms.

Viscarret, F. y Pedraza, O. (Directores). (2020). Patria [Serie de televisión]. Alea Media. Recuperado de https://es.hboespana.com/

Weiner, M. (Director). (2007-2015). Mad Men. [Serie de televisión]. AMC.

\section{Uso de imágenes}

Las imágenes utilizadas como figuras en este artículo son elementos centrales del análisis, realizado únicamente con fines científicos en el ámbito académico. 


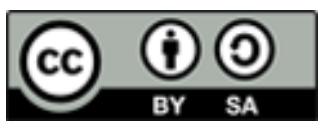

Licencia Creative Commons

Miguel Hernández Communication Journal

mhjournal.org

\section{Cómo citar este texto:}

Ana Quiroga Álvarez (2021): Interacciones entre lo nacional y lo corpóreo. El caso de Arantxa en la serie Patria, en Miguel Hernández Communication Journal, Vol 12 (2) pp. 311 a 331. Universidad Miguel Hernández, UMH (Elche-Alicante). DOI: 10.21134/mhjournal. v12i.1327 